\title{
Influence of Ba-to-Si deposition rate ratios on the electrical and optical properties of $\mathrm{B}$-doped $\mathrm{BaSi}_{2}$ epitaxial films
}

Shu Sugiyama, Yudai Yamashita, Kaoru Toko, and Takashi Suemasu

Institute of Applied Physics, University of Tsukuba, Tsukuba, Ibaraki 305-8573, Japan

\begin{abstract}
$\mathrm{BaSi}_{2}$ is considered a candidate for a light absorbing layer of a solar cell. The carrier type, carrier density, and photoresponsivity of undoped $\mathrm{BaSi}_{2}$ films depend on Ba-to-Si deposition rate ratios $\left(R_{\mathrm{Ba}} / R_{\mathrm{Si}}\right)$ during molecular beam epitaxy (MBE). In this study, we examined these properties of $\mathrm{B}$-doped $\mathrm{BaSi}_{2}$ epitaxial films grown by $\mathrm{MBE}$. We fabricated 0.5 - $\mu \mathrm{m}$-thick lightly B-doped $\mathrm{BaSi}_{2}$ epitaxial films on $\mathrm{Si}$ (111) substrates at a substrate temperature of $600{ }^{\circ} \mathrm{C} . R_{\mathrm{Ba}} / R_{\mathrm{Si}}$ was varied in the range $1.0-5.6$ and the $\mathrm{B}$ concentration was set at about $10^{16} \mathrm{~cm}^{-3}$. The p-type $\mathrm{BaSi}_{2}$ films were formed only in the range of $R_{\mathrm{Ba}} / R_{\mathrm{Si}}=2.1-2.9$, whereas $\mathrm{BaSi}$ formed with other values of $R_{\mathrm{Ba}} / R_{\mathrm{Si}}$ showed $\mathrm{n}$ type conductivity. The photoresponsivity significantly depended on $R_{\mathrm{Ba}} / R_{\mathrm{Si}}$, and reached values higher than those obtained for undoped $\mathrm{BaSi}_{2}$ films. We ascribed the enhancement of photoresponsivity to $\mathrm{B}$ atoms making $\mathrm{Si}$ vacancies inactive in $\mathrm{B}$-doped $\mathrm{BaSi}_{2}$ films.
\end{abstract}




\section{INTRODUCTION}

Currently, crystalline Si solar cells occupy more than $90 \%$ of the solar cell market. However, its conversion efficiency $\eta$ has reached $26.7 \%$ at the research stage. ${ }^{1)}$ This value is close to the theoretical limit. $\left.{ }^{2}\right)$ Therefore, various materials have been extensively studied for solar cell applications. Solar cells using III-V compound semiconductors such as GaAs achieve higher $\eta$ than Si solar cells. ${ }^{3)}$ However, those solar cells are expensive and therefore larger-scale deployment is not easy. Under these circumstances, we have focused on orthorhombic $\mathrm{BaSi}_{2}$ as a solar cell material which can be fabricated on a $\mathrm{Si}$ substrate. ${ }^{4-6)} \mathrm{BaSi}_{2}$ is a rare earth-free and nontoxic semiconductor. Besides, it consists of abundant elements, $\mathrm{Ba}$ and $\mathrm{Si}$. $\mathrm{BaSi} 2$ possesses a suitable bandgap $(1.3 \mathrm{eV})$ for a singlejunction solar cell, and a high optical absorption coefficient $\alpha=3 \times 10^{4} \mathrm{~cm}^{-1}$ at $1.5 \mathrm{eV}$, which is more than 40 times as large as that of crystalline $\mathrm{Si}^{7-10)}$ Moreover, its minority carrier diffusion length is about $10 \mu \mathrm{m},{ }^{11)}$ which is sufficiently large as a thin film solar cell material. Due to these attractive features, $\mathrm{BaSi}_{2}$ is expected to be a new candidate for high- $\eta$ thin film solar cells. So far, various properties of $\mathrm{BaSi}_{2}$ films have been investigated. Regarding control of carrier type and carrier concentration, we succeeded to control hole and electron concentrations in the range $10^{16}-10^{19} \mathrm{~cm}^{-3}$ by using $\mathrm{B}$ and $\mathrm{Sb}$ as dopants, respectively. ${ }^{12-14)}$ In addition, we achieved a large minority carrier lifetime $(\tau$ $\sim 10 \mu \mathrm{s}$ ) thanks to a-Si passivation layers. ${ }^{15-17)}$ By using these techniques, we have achieved $\eta$ approaching $10 \%$ in $\mathrm{p}-\mathrm{BaSi}_{2} / \mathrm{n}$-Si heterojunction solar cells. ${ }^{18-20)}$ This value is the highest ever achieved for solar cells using semiconducting silicides. As a next step, we target to achieve $\mathrm{BaSi}_{2}$ homojunction solar cells. ${ }^{21)}$ Recently, we have demonstrated the operation of homojunction solar cells, wherein the optical absorbing layer was lightly B-doped $\mathrm{BaSi}_{2}{ }^{21,22)}$ However, the $\eta$ was as low as $0.28 \%{ }^{22)}$ We attribute such a small $\eta$ 
to defects in the $\mathrm{BaSi}_{2}$ light absorbing layer. First-principle calculations based on VASP code show that $\mathrm{Si}$ vacancies $\left(\mathrm{V}_{\mathrm{Si}}\right)$ are most likely to occur in $\mathrm{BaSi} 2$ regardless of $\mathrm{BaSi}_{2}$ formed under Si-rich or Si-poor (Ba-rich) conditions, ${ }^{23)}$ and $\mathrm{V}_{\mathrm{Si}}$ form localized states within the bandgap, and thereby acts as recombination centers. Thus, we need to fabricate high-quality $\mathrm{BaSi}_{2}$ epitaxial films with a low defect density. In our previous study, ${ }^{24)}$ it was proven that Ba-to-Si deposition rate ratios $\left(R_{\mathrm{Ba}} / R_{\mathrm{Si}}\right)$ during molecular beam epitaxy (MBE) has an enormous impact on carrier type, carrier concentration, and photoresponsivity. Especially, in the case of undoped $\mathrm{BaSi}_{2}$ ones, the carrier concentration reached a minimum and therefore the photoconductivity reached a maximum at $R_{\mathrm{Ba}} / R_{\mathrm{Si}}=$ 2.2 when grown at $580{ }^{\circ} \mathrm{C} .{ }^{24)}$ Therefore it is considered reasonable that the electrical and optical properties of lightly B-doped $\mathrm{BaSi} 2$ epitaxial films depend also on $R_{\mathrm{Ba}} / R_{\mathrm{Si}}$. In this study, we fabricated lightly B-doped $\mathrm{BaSi}_{2}$ epitaxial films using various values of $R_{\mathrm{Ba}} / R_{\mathrm{Si}}$ $=1.0-5.6$ on $\mathrm{Si}(111)$ substrates and evaluated their electrical and optical properties.

\section{EXPERIMENTAL METHOD}

We fabricated lightly B-doped $\mathrm{BaSi}_{2}$ epitaxial films on Si (111) substrates with MBE system equipped with an electron-beam evaporation source for $10 \mathrm{~N}-\mathrm{Si}$ and standard Knudsen cells for 3N-Ba and $\mathrm{B}$. We used floating-zone (FZ) n-Si(111) substrates (resistivity $\rho>10000 \Omega \mathrm{cm}$ ) for Hall-effect measurement and microwave-detected photoconductivity decay ( $\mu$-PCD) measurement. On the other hand, we used Czochralski (CZ) n-Si(111) substrate $(\rho<0.01 \Omega \cdot \mathrm{cm})$ for photoresponsivity measurement. Before fabricating the $\mathrm{BaSi}_{2}$ epitaxial films, we cleaned the Si substrate surfaces by RCA (Radio Corporation of America) procedure so that we can cover the surface with a protective 
oxide layer. Then, we removed the oxide layer by heating the substrate at a temperature $\left(T_{\mathrm{S}}\right)$ of $900^{\circ} \mathrm{C}$ in the ultra-high vacuum chamber. Next, we formed 5-nm-thick $\mathrm{BaSi}_{2}$ template layers by depositing Ba on a Si substrate at $T_{\mathrm{S}}=500{ }^{\circ} \mathrm{C} .{ }^{25)} \mathrm{We}$ call this procedure reactive deposition epitaxy. Under this procedure, $R_{\mathrm{Ba}}$ was set at $1 \mathrm{~nm} / \mathrm{min}$. After that, we grew $0.5-\mu$ m-thick B-doped $\mathrm{BaSi}_{2}$ films on the templates by $\mathrm{MBE}$ at $T_{\mathrm{S}}=600{ }^{\circ} \mathrm{C} .{ }^{19}$ ) During the MBE growth, $R_{\mathrm{Si}}$ was fixed to be $0.9 \mathrm{~nm} / \mathrm{min}$ and $R_{\mathrm{Ba}}$ was varied from 0.9 to $5.0 \mathrm{~nm} / \mathrm{min}$, giving a variation of $R_{\mathrm{Ba}} / R_{\mathrm{Si}}$ from 1.0 to 5.6 . We set the $\mathrm{B}$ crucible temperature at $1100{ }^{\circ} \mathrm{C}$ for $\mathrm{B}$ concentration to be approximately $10^{17} \mathrm{~cm}^{-3}$. We then formed a 3-nm-thick a-Si capping layer in situ at $180{ }^{\circ} \mathrm{C}$, which acts as a surface passivation layer. ${ }^{26,27)}$ Finally, indium-tin-oxide (ITO) electrodes with a diameter of $1 \mathrm{~mm}$ and a thickness of $80 \mathrm{~nm}$ were sputtered on the surface, and Al electrodes were formed on the entire back surface. In this study, we used reflection high-energy electron diffraction (RHEED) and x-ray diffraction (XRD; RIGAKU Smart Lab), Raman spectroscopy (JASCO NRS -5100) equipped with a frequency-doubled Nd:YAG laser $(532 \mathrm{~nm}, 5.1 \mathrm{~mW})$ to characterize crystalline quality of grown films. The time of acquisition for each Raman spectrum was $100 \mathrm{~s}$. The absolute Raman shift was corrected by the transverse optical (TO) phonon line $\left(520.2 \mathrm{~cm}^{-1}\right)$ of crystalline Si.

Photoresponsivity was evaluated using a lock-in technique with a xenon lamp and a 25-cm-focal-length single monochromator (Bunko Keiki SM-1700A and RU-60N). The light intensity was calibrated with a pyroelectric sensor (Melles Griot 13PEM001/J). All measurements were carried out at room temperature (RT).

\section{RESULTS AND DISCUSSION}

Figure 1 shows the $\theta-2 \theta \mathrm{XRD}$ and RHEED patterns after MBE of $\mathrm{B}$-doped $\mathrm{BaSi}_{2}$ 
layers with different values of $R_{\mathrm{Ba}} / R_{\mathrm{Si}}$. Regardless of $R_{\mathrm{Ba}} / R_{\mathrm{Si}}, a$-axis-oriented diffraction peaks of $\mathrm{BaSi}_{2}$ in the XRD patterns can be observed together with streaky and spot RHEED patterns. This means that $a$-axis-oriented $\mathrm{BaSi}_{2}$ films were grown epitaxially on the Si (111) substrates. While sharp streaky RHEED patterns were observed at $R_{\mathrm{Ba}} / R_{\mathrm{Si}}=$ $1.0-3.9$, the sample grown with $R_{\mathrm{Ba}} / R_{\mathrm{Si}}=5.6$ shows spot RHEED patterns, indicating that the surface of $\mathrm{BaSi}_{2}$ epitaxial films was not smooth at $R_{\mathrm{Ba}} / R_{\mathrm{Si}}=5.6$. On the other hand, with the decrease of $R_{\mathrm{Ba}} / R_{\mathrm{Si}}$, thereby for $\mathrm{BaSi}_{2}$ films grown under Si-rich conditions, the diffraction intensity of each peak gradually decreased, meaning that the crystalline quality of $\mathrm{BaSi}_{2}$ films was degraded

Figure 2 shows the Raman spectra of $\mathrm{BaSi}_{2}$ films in the range between 200 and $700 \mathrm{~cm}^{-1}$. We observed five peaks which originate from the internal vibrations of $\mathrm{Si}$ tetrahedra in the $\mathrm{BaSi}_{2}$ lattice. ${ }^{28)}$ For samples grown under Si-rich conditions, $R_{\mathrm{Ba}} / R_{\mathrm{Si}}=$ 1.0 and 1.4, the transverse optical phonon line of $\mathrm{Si}$ ( $\mathrm{Siто)} \mathrm{was} \mathrm{observed.} \mathrm{The} \mathrm{absorption}$ coefficient of $\mathrm{BaSi}_{2}$ at a wavelength of the excited laser light (532nm) is $\alpha=3 \times 10^{5} \mathrm{~cm}^{-1}$.) Hence, the penetration depth of the laser light is about $1 / \alpha \times 3 \approx 0.1 \mu \mathrm{m}$. This value is much smaller than the $\mathrm{BaSi}_{2}$ layer thickness. Thus, the $\mathrm{Si}$ то signal was interpreted to originate from Si precipitated in the $\mathrm{BaSi}_{2}$ films. This is because the $\mathrm{BaSi}_{2}$ films in these samples were grown under Si-rich conditions. Thus, excess Si atoms might agglomerate to form Si precipitates in the $\mathrm{BaSi}_{2}$ films.

Figure 3 shows the results of Hall measurements. Depending on $R_{\mathrm{Ba}} / R_{\mathrm{Si}}$, the conduction type and carrier concentration of $\mathrm{B}$-doped $\mathrm{BaSi}_{2}$ films changed as shown in Fig. 3(a). In the case of B-doped $\mathrm{BaSi}_{2}$ films with $R_{\mathrm{Ba}} / R_{\mathrm{Si}}=2.1-2.9$, the conduction type was p-type. At $R_{\mathrm{Ba}} / R_{\mathrm{Si}}=2.4$, a hole concentration was $2 \times 10^{17} \mathrm{~cm}^{-3}$, and a hole mobility was $112 \mathrm{~cm}^{2} / \mathrm{Vs}$. The valence band maximum of $\mathrm{BaSi}_{2}$ is mostly composed of the $\mathrm{Si} \mathrm{p}$ state in $\mathrm{BaSi}_{2}$. Hence, we expect that the replacement of some $\mathrm{Si}$ atoms in $\mathrm{BaSi}_{2}$ by a group 13 element like $\mathrm{B}$ will decrease the valence electron concentration and cause $\mathrm{BaSi}_{2}$ to become p-type semiconductor. ${ }^{8-10,29)}$ On the other hand, for B-doped $\mathrm{BaSi}_{2}$ films grown under Ba-rich conditions $\left(R_{\mathrm{Ba}} / R_{\mathrm{Si}}>3.9\right)$ and Si-rich conditions $\left(R_{\mathrm{Ba}} / R_{\mathrm{Si}}<1.4\right)$, the 
conduction type was n-type in spite of B doping. We assumed that a large number of $\mathrm{V}_{\mathrm{Si}}$ gave rise to electrons, and thus the electron concentration became higher than the residual hole concentration caused by $\mathrm{B}$ atoms, leading to the formation of $\mathrm{n}-\mathrm{BaSi}_{2}$ films. Note that there is a marked difference in measured mobility between electrons and holes in Fig. 3(b). However, there is not so much difference between them according to theoretical calculations in Ref. [8]; the effective masses of electron and hole are calculated to be $0.41 m_{0}$ and $0.53 m_{0}$, respectively. Here, $m_{0}$ is the free electron mass. Therefore, we ascribe such a large difference in mobility to different scattering mechanisms in lightly B-doped $\mathrm{BaSi}_{2}$ films, discussed in Ref [30].

Figures 4(a) and 4(b) shows photoresponse spectra of undoped $\mathrm{BaSi}_{2}$ and $\mathrm{B}$ doped $\mathrm{BaSi}_{2}$ films grown with various values of $R_{\mathrm{Ba}} / R_{\mathrm{Si}}$. A bias voltage $V_{\text {bias }}=-1.0 \mathrm{~V}$ was applied to the front-surface ITO electrode with respect to the back-surface Al electrode to extract the photogenerated holes in the $\mathrm{BaSi}_{2}$ films to the ITO electrode. In the case of $\mathrm{B}$-doped $\mathrm{BaSi} 2$ films, the photoresponsivity became a maximum at $R_{\mathrm{Ba}} / R_{\mathrm{Si}}=$ 2.1. As shown in Fig. $2, R_{\mathrm{Ba}} / R_{\mathrm{Si}}=2.1$ is the smallest value below which $\mathrm{Si}$ то lines marked by red circles appears, meaning the formation of Si precipitates. This trend is the same as those obtained for undoped $\mathrm{BaSi}_{2}$ films. ${ }^{31)}$ In comparison with undoped one, lightly Bdoped $\mathrm{BaSi}_{2}$ films show much higher photoresponsivity as shown in Figs. 4(a) and 4(b). It is reasonable to consider that the carrier lifetime is improved for lightly B-doped $\mathrm{BaSi}_{2}$ films. In this work, the photoresponsivity of $\mathrm{BaSi}_{2}$ films was measured using the photoconduction effect. Therefore, the photoresponsivity is roughly proportional to the carrier lifetime. ${ }^{32)}$ Therefore, we attribute the increase in photoresponsivity to the increase of carrier lifetime by the decrease of point defects in B-doped $\mathrm{BaSi}_{2}$ films. In undoped $\mathrm{BaSi}_{2}$ films, photoresponsivity and carrier lifetime improved significantly by hydrogen 
(H) passivation. ${ }^{33)} \mathrm{H}$ atoms in $\mathrm{BaSi}_{2}$ films are considered to inactivate $\mathrm{V}_{\mathrm{Si}}$, which are most likely to form in $\mathrm{BaSi}_{2 .}{ }^{23)}$ Likewise, we speculate that doping B atoms make $\mathrm{V}_{\text {Si }}$ inactive in B-doped BaSi2 films.

\section{CONCLUSION}

We fabricated 0.5- $\mu \mathrm{m}$-thick lightly B-doped $\mathrm{BaSi}_{2}$ epitaxial films with different values of $R_{\mathrm{Ba}} / R_{\mathrm{Si}}$, and evaluated their electrical and optical properties. From XRD measurement, the epitaxial growth of $a$-axis-oriented $\mathrm{BaSi}_{2}$ films were confirmed for all of the samples. The $\mathrm{p}-\mathrm{BaSi}_{2}$ films were formed only at $R_{\mathrm{Ba}} / R_{\mathrm{Si}}=2.1-2.9$. From Raman spectroscopy measurement, we found that the SiTo phonon line appeared in B-doped BaSi2 epitaxial films under the conditions of $R_{\mathrm{Ba}} / R_{\mathrm{Si}} \leq 1.4$. The photoresponsivity was the highest when $R_{\mathrm{Ba}} / R_{\mathrm{Si}}$ was a little larger than the point at which the $\mathrm{Si}^{\mathrm{TO}}$ peak increased. This result was the same as that obtained for undoped $\mathrm{BaSi}_{2}$ films. B-doped $\mathrm{BaSi}_{2}$ epitaxial films at $R_{\mathrm{Ba}} / R_{\mathrm{Si}}=2.1$ showed higher photoresponsivity than undoped $\mathrm{BaSi} 2$ epitaxial film. Therefore, this result shows that lightly B-doped $\mathrm{BaSi}_{2}$ films are more promising as a light absorbing layer than undoped $\mathrm{BaSi}_{2}$ films.

\section{ACKNOWLEDGEMENTS}

This work was financially supported by JSPS KAKENHI Grant Numbers 17K18865 and 18H03767. One of the authors (Y.Y.) was financially supported by a Grant-in-Aid for JSPS Fellows (19J21372). 
Fig. $1 \theta-2 \theta \mathrm{XRD}$ and RHEED patterns of B-doped $\mathrm{BaSi}_{2}$ films with $R_{\mathrm{Ba}} / R_{\mathrm{Si}}=1.0-5.6$.

Fig. 2 Raman spectra of B-doped $\mathrm{BaSi}_{2}$ films with $R_{\mathrm{Ba}} / R_{\mathrm{Si}}=1.0-5.6$. Vibrational modes due to Si tetrahedral in the lattice of $\mathrm{BaSi} 2$ are denoted by $\mathrm{Fg}, \mathrm{Eg}$, and $\mathrm{Ag}$. Red broken circles indicate the peak of Siтo.

Fig. 3 (a) Carrier concentration and (b) mobility of B-doped $\mathrm{BaSi}_{2}$ films as a function of $R_{\mathrm{Ba}} / R_{\mathrm{Si}}$. B-doped $\mathrm{BaSi} 2$ films show p-type conductivity in the $R_{\mathrm{Ba}} / R_{\mathrm{Si}}$ range $2.1-2.9$.

Fig. 4 Photoresponse spectra of (a) B-doped $\mathrm{BaSi}_{2}$ films and (b) undoped $\mathrm{BaSi}_{2}$ films grown with various values of $R_{\mathrm{Ba}} / R_{\mathrm{Si}}$. 


\section{References}

1) K. Yoshikawa, H. Kawasaki, W. Yoshida, K. Konishi, K. Nakano, T. Uto, D. Adachi, M. Kakematsu, H. Uzu, and K. Yamamoto, Nat. Energy 2, 17032 (2017).

2) W. Shockley and H. J. Queisser, J. Appl. Phys. 32, 510 (1961).

3) Press Release, Fraunhofer Institute for Solar Energy Systems, 1 December (2014).

4) T. Suemasu and N. Usami, J. Phys. D 50, 023001 (2017).

5) M. Imai and T. Hirano, J. Alloys Compd. 224, 111 (1995).

6) R. A. McKee and F. J. Walker, Appl. Phys. Lett. 63, 2828 (1993).

7) K. Toh, T. Saito, and T. Suemasu, Jpn. J. Appl. Phys. 50, 068001 (2011).

8) D. B. Migas, V. L. Shaposhnikov, and V. E. Borisenko, Phys. Status Solidi B 244, 2611 (2007).

9) M. Kumar, N. Umezawa, and M. Imai, J. Appl. Phys. 115, 203718 (2014).

10) M. Kumar, N. Umezawa, and M. Imai, Appl. Phys. Express 7, 071203 (2014).

11) M. Baba, K. Toh, K. Toko, N. Saito, N. Yoshizawa, K. Jiptner, T. Sakiguchi, K. O. Hara, N. Usami, and T. Suemasu, J. Cryst. Growth 348, 75 (2012).

12) M. A. Khan, K. O. Hara, W. Du, M. Baba, K. Nakamura, M. Suzuno, K. Toko, N. Usami, and T. Suemasu, Appl. Phys. Lett. 102, 112107 (2013).

13) M. A. Khan, K. Nakamura, W. Du, K. Toko, N. Usami, and T. Suemasu, Appl. Phys. Lett. 104, 252104 (2014).

14) M. Kobayashi, Y. Matsumoto, Y. Ichikawa, D. Tsukada, and T. Suemasu, Appl. Phys. Express 1, 051403 (2008).

15) K. O. Hara, N. Usami, K. Toh, M. Baba, K. Toko, and T. Suemasu, J. Appl. Phys. 112, 083108 (2012).

16) K. O. Hara, N. Usami, K. Nakamura, R. Takabe, M. Baba, K. Toko, and T. Suemasu, Appl. Phys.

17) R. Takabe, K. O. Hara, M. Baba, W. Du, N. Shimada, K. Toko, N. Usami, and T. Suemasu, J. Appl. Phys. 115, 193510 (2014).

18) S. Yachi, R. Takabe, K. Toko, and T. Suemasu, Appl. Phys. Lett. 109, 072103 (2016).

19) D. Tsukahara, S. Yachi, H. Takeuchi, R. Takabe, W. Du, M. Baba, Y. Li, K. Toko, N. Usami, and T. Suemasu, Appl. Phys. Lett. 108, 152101 (2016).

20) T. Deng, T. Sato, Z. Xu, R. Takabe, S. Yachi, Y. Yamashita, K. Toko, and T. Suemasu, Appl. Phys. Express 11, 6 (2018).

21) K. Kodama, R. Takabe, T. Deng, K. Toko, and T. Suemasu, Jpn. J. Appl. Phys. 57, 050310 (2018).

22) K. Kodama, Y. Yamashita, K. Toko, and T. Suemasu, Appl. Phys. Express 12, 041005 (2019). 
23) M. Kumar, N. Umezawa, W. Zhou, and M. Imai, J. Mater. Chem. A 5, 25293 (2017).

24) R. Takabe, T. Deng, K. Kodama, Y. Yamashita, T. Sato, K. Toko, and T. Suemasu, J. Appl. Phys. 123, 045703 (2018).

25) Y. Inomata, T. Nakamura, T. Suemasu, and F. Hasegawa, Jpn. J. Appl. Phys. 43, 4155 (2004).

26) R. Takabe, S. Yachi, W. Du, D. Tsukahara, H. Takeuchi, K. Toko, and T. Suemasu, AIP Advances 6, 085107 (2016).

27) R. Takabe, H. Takeuchi, W. Du, K. Ito, K. Toko, S. Ueda, A. Kimura, and T. Suemasu, J. Appl. Phys. 119, 165304 (2016).

28) H. Hoshida, N. Murakoso, T. Suemasu, and Y. Terai, Defect and Diffusion Forum 386, 43 (2018).

29) Y. Imai, A. Watanabe, and M. Mukaida, J. Alloys Compd. 385, 257 (2003).

30) T. Deng, T. Suemasu, D. A. Shohonov, I. S. Samusevich, A. B. Filonov, D. B. Migas, and V. E. Borisenko, Thin Solid Films 661, 7 (2018).

31) Y. Yamashita, T. Sato, K. Toko, A. Uedono, and T. Suemasu, Appl. Phys. Express 12, 055506 (2019).

32) S. M. Sze, Physics of Semiconductor Devices, 2nd ed. (Wiley, New York, 1981).

33) Z. Xu, D. A. Shohonov, A. B. Filonov, K. Gotoh, T. Deng, S. Honda, K. Toko, N. Usami, D. B. Migas, V. E. Borisenko, and T. Suemasu, Phys. Rev. Mater. 3, 065403 (2019). 


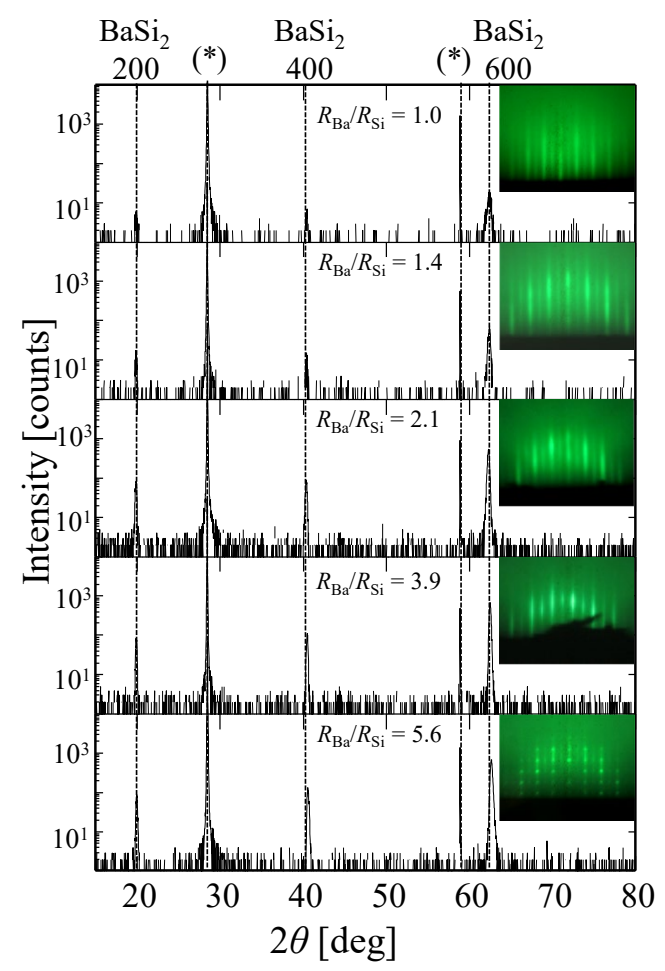

Fig. 1 


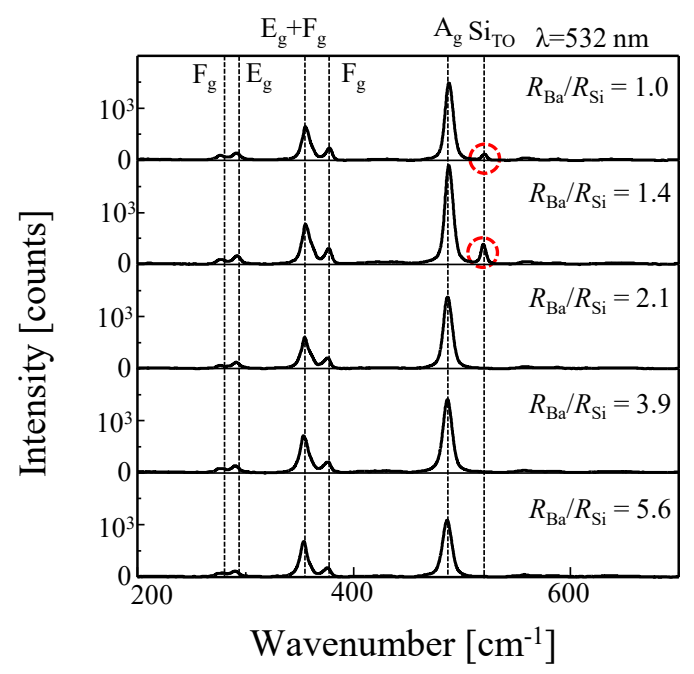

Fig. 2 

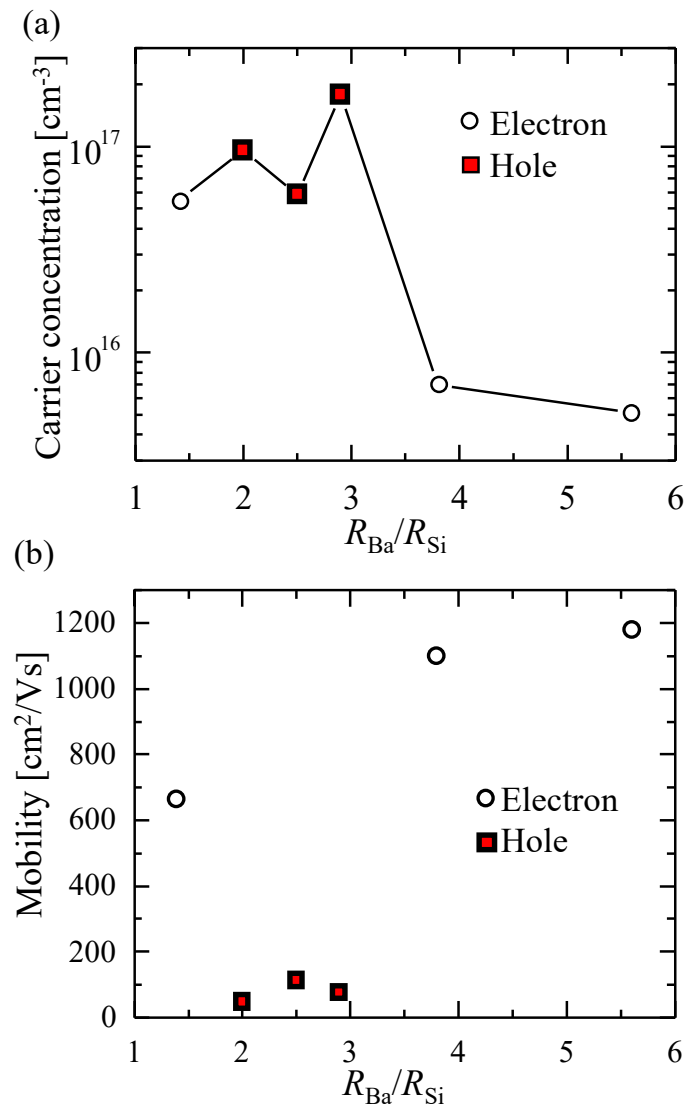

Fig. 3 

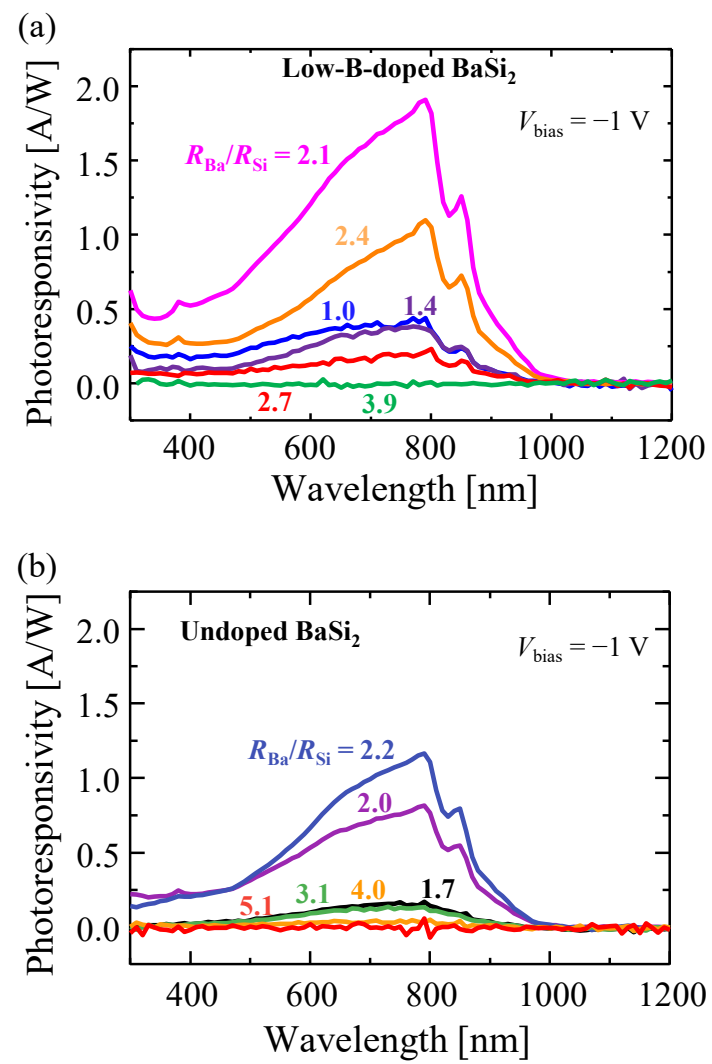

Fig. 4 